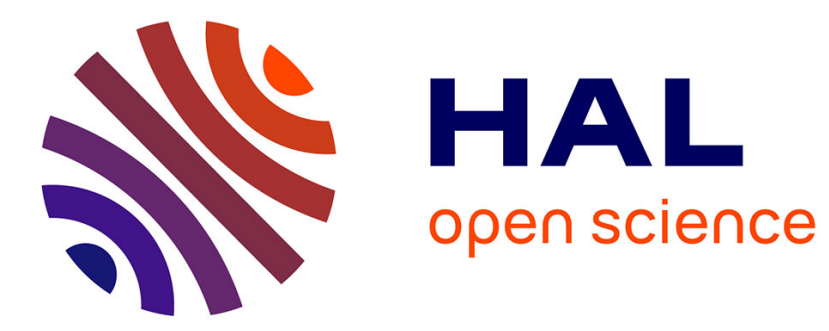

\title{
Beyond the Stern Review: Lessons from a risky venture at the limits of the cost-benefit analysis
}

\author{
Jean-Charles Hourcade, Philippe Ambrosi, Patrice Dumas
}

\section{To cite this version:}

Jean-Charles Hourcade, Philippe Ambrosi, Patrice Dumas. Beyond the Stern Review: Lessons from a risky venture at the limits of the cost-benefit analysis. Ecological Economics, 2009, 68 (10), pp.2479-

2484. 10.1016/j.ecolecon.2009.04.011 . hal-00716769

\section{HAL Id: hal-00716769 \\ https://hal-enpc.archives-ouvertes.fr/hal-00716769}

Submitted on 7 Apr 2015

HAL is a multi-disciplinary open access archive for the deposit and dissemination of scientific research documents, whether they are published or not. The documents may come from teaching and research institutions in France or abroad, or from public or private research centers.
L'archive ouverte pluridisciplinaire HAL, est destinée au dépôt et à la diffusion de documents scientifiques de niveau recherche, publiés ou non, émanant des établissements d'enseignement et de recherche français ou étrangers, des laboratoires publics ou privés. 
The published version of this paper is available at http://dx.doi.org/10.1016/j.ecolecon.2009.04.011. Jean-Charles Hourcade, Philippe Ambrosi, Patrice Dumas, Beyond the Stern Review: Lessons from a risky venture at the limits of the cost-benefit analysis, Ecological Economics, Volume 68, Issue 10, 15 August 2009, Pages 2479-2484, ISSN 0921-8009, DOI: 10.1016/j.ecolecon.2009.04.011.

\title{
Beyond the Stern Review: lessons from a risky venture at the limits of the cost-benefit analysis
}

\author{
Jean-Charles HOURCADE (CIRED) $)^{1}$
}

Philippe Ambrosi (World Bank) ${ }^{2}$

Patrice Dumas (LMD) $)^{3 \mathrm{c}}$

\begin{abstract}
:
This paper argues that debates amongst economists triggered by the Stern Review are partly relevant, focusing on key parameters translating real ethical issues, and partly misplaced in that they do not consider enough other determinants of climate change damages: i) the specifications of the utility function used for the assessments (preference for the environment, preference for smooth growth paths), ii) the interplay between uncertainty and the sequentiality of the decision, and iii) whether the growth engines behind the integrated assessment models can account for transient disequilibrium and sub-optimality. We derive some suggestions for any future research agenda in integrated assessment modelling, whatever the position of the analysts about the relevance of the inter-temporal optimisation framework and the Bayesian approach to uncertainty in the climate affair.
\end{abstract}

\section{Key words:}

Discounting, damage assessment, environmental value, integrated assessment model, uncertainty, cost-benefit analysis, information value, decision-making, irreversibility, adaptation, social preference, non-market impacts, intergenerational equity, intragenerational equity.

Introduction

\footnotetext{
${ }^{1}$ Centre International de Recherches sur l'Environnement et le Développement, a joint Research Center of CNRS, Ecole des Hautes Etudes en Sciences Sociales, AgroParistech, Université Paris-Est, Centre International de Recherches sur l'Agriculture et le Développement.

${ }^{2}$ The findings and opinions expressed in this paper are the sole responsibility of the author. They do not necessarily reflect the views of the World Bank, its Executive Directors nor of the countries they represent.

${ }^{3}$ Laboratoire de Météorologie Dynamique. The author acknowledges financial support from the Ile de France region, under the R2DS research programme.

c Corresponding author, dumas@centre-cired.fr. We would like to thank two anonymous reviewers for their very useful comments that helped clarifying and enhancing the article.
} 
Undoubtedly, the media success of the Stern Review (Stern, 2006), in addition to its richness, is due to an alarming assessment of climate change damages, calling for "strong and early action", being delivered by a former Chief Economist of the World Bank and not by an ecologist activist. It was both praised ${ }^{4}$ and harshly criticized ${ }^{5}$ by the different leanings of the economic profession which concentrated on two controversial parameters of critical importance for a cost-benefit analysis (CBA), i.e. the pure time preference (PTP) and the curvature of the function linking consumption to its utility.

It is remarkable that this debate developed essentially amongst the tenants of the conventional CBA framework and did not mobilize so much those who, reluctant to monetizing damages and sceptical about applying intertemporal optimisation over one century, experienced alternative frameworks such as the Tolerable Windows or the Safe Corridor Approach (Petschel-Held et al, 1999; Tóth, 2003) with more complex and multi-disciplinary models but an explicit acceptance of normative targets not grounded in an economic framework. From their perspective, the Stern report is a risky and desperate venture to expand conventional CBA beyond its scope of relevance.

The bottom line of this paper is to start from an internal appraisal of the dispute, i.e. accepting the discounted utility criterion as an appropriate framework in the climate affair. This appraisal will be used to spell out a set of methodological issues to be tackled by new generations of integrated assessment of climate policies. These issues concern all analysts including the sceptics about the conventional economic toolbox. The Ariadne's thread of this appraisal is made up with two diagnoses:

- the gap between Stern's detailed description of climate change impacts and the methodology used for their aggregate valuation. He casts serious doubts about the chief assumption behind low estimates of climate damages (Mendelsohn et al, 2000; Tol 2002b), namely that societies can adapt to an evolving climate with no significant transition costs. However his toolbox fails to incorporate the key element of this diagnosis, namely the disequilibrium dynamics possibly triggered by the interplays between social and environmental changes;

- the fact that, perhaps driven by a professional reflex of using very stylised models whose analytical control is possible, and attracted by the revival of a familiar dispute, many economists did not focus the discussion on this gap. They rather conducted controversies on the discount rate and to a lesser extent on the elasticity of the marginal utility of consumption, at the risk of overshadowing the assessment of climate damages by the debates around a couple of very fragile parameters.

We first show that the value of the PTP is not the only component of the preference system that matters for the trade-off between the short term and the long term. We then show that this parameter is less critical in a sequential decision-making approach because of the importance of the value of information and of its many determinants. In a third step, we question the vision of the economic growth engine and of intragenerational equity that underpins conventional CBA.

\section{Trade-offs between the short and long terms: the role of the preference systems}

\footnotetext{
4 A selection of comments to the Stern review can be accessed http://www.hmtreasury.gov.uk/media/1/2/20061028_Quotes-7.pdf

${ }^{5}$ See for instance, Dasgupta (2006), Mendelsohn (2006), Nordhaus (2006), Tol and Yohe (2006), Weitzman (2007a), to name only a few.
} 
The harshest debates about the Stern Review relate to the selection of a very low pure time preference (PTP) to assess climate change damages and climate policies ${ }^{6}$. They in fact repeat an old dispute (Ramsey vs. Koopmans), which is likely not to come to an end because it intrinsically incorporates a positive dimension (how people do really behave) and a normative one (how we should behave) (Arrow et al., 1995). This dispute is indeed framed around the Ramsey equation ( $r=\boldsymbol{\beta} \boldsymbol{n g} . \quad$ ) which is a catchy way to capture the interactions between critical aspects of preferences ( $\rho$ as the PTP and $\eta$ as the elasticity of the marginal utility of consumption) and technical change ( $r$ as the marginal productivity of capital and $g$ the resulting growth of consumption) along an optimal growth pathway.

To align the social discount rate on the economic growth rate is no longer controversial amongst economists specialized in this field: if future generations are richer, it is ethically legitimate to consider that the same burden (a mitigation cost or a damage cost) will affect less their welfare than that of current generations. There is no contention as well against retaining discount rates corresponding to the most pessimistic assumptions in a context of uncertainty about economic growth (Newell and Pizer, 2001; Weitzman, 1998): in a stochastic framework, the least value of the discount rate tends to dominate in the far distant future and drives the results of the analysis. Along the same line hold the arguments of Heal (2005) and Dasgupta (1999) that, if environmental disruption slows down economic growth, the discount rates should be lower.

The value of $\rho$, that governs the gap between the discount rate and the economic growth rate, is more contentious because of its inevitable ethical consequences. The difficulty is that it makes sense in a formula stemming from what R. Hahn called a "ramseyification of the Solow's model"7: it is used for normative analysis but, to inform public policy, it pretends to describe a reasonable state of the world. Over a one century time horizon, this does not mean a likely or best guess prediction but, at least, to secure that a given scenario, resulting from a specific worldview about the world future generations will experience, does not contain an intrinsic inconsistency. This imposes that $\rho$ cannot be selected totally independently from the other parameters of the projection.

Let us admit, like Stern, that the uncertainty about the existence of generations yet to be born is the only ethical justification for discounting utility and that this justifies a $0.01 \%$ PTP ${ }^{8}$. The calibration of the model should make this value consistent with values of $\eta, r$, and $g$ leading to plausible and consistent projections of future economies. Selecting an arbitrary PTP all other parameters equal and without such a consistency check has indeed profound ethical consequences. The most important one was well perceived in the early attempts to use à la Ramsey models for economic planning in the fifties a non-null $\rho$ prevents the social planner from sacrificing the current generation in the name of a brighter future (Stoleru, 1968) ${ }^{9}$ by preventing important capital accumulation today to maximize consumption in the long term. Actually the magnitude of this 'sacrifice' is ultimately depending upon

\footnotetext{
${ }^{6}$ See elements of responses to criticisms on this respect in Stern Review team (2007).

Franck Hahn used this expression in a collection of essays to celebrate Bob Solow (Hahn, 1990), noting that adding perfect foresight to the Solow model 'is its proper consummation'. The reason is that it endogenises the savings function, the core of the model, which leads to a model that 'may " fit » some time series' but 'does not aid understanding' (p. 27). The oversight of this type of caveat may be one reason why the use (and criticisms) of «ramseyified Solow models » in the climate affair triggered a permanent mix of normative judgments and positive analyses of the real world.

${ }^{8}$ Here a 0.95 probability they will exist in 2100 . This argument joins the positions of Ramsey, Sen or Solow.

${ }^{9}$ A similar interpretation of discounting can be found in Chichilnyski et al.(1995) who proposes a formula to protect the last generation without sacrificing the current ones.
} 
assumptions regarding capital deepening and capital productivity, which determine the links between savings and future consumption flows.

The same consistency check should also apply on any alternative proposal for weighting current and future generations to compensate for the role of the PTP in discounting on long term horizons. One of these proposals has been to adjust the elasticity of the marginal utility of income. The Stern assumption ( $\eta=1$ ) has been contested by Gollier (2006) and Weitzman who suggest $\eta=2$ to reflect risk-aversion in a consistent way with the risk premium revealed on insurance markets. Given that the Stern Review deals with uncertainties about climate change damages through a Monte Carlo technique picking 1000 possible scenarios and selecting $\eta=2$ instead of $\eta=1$ would indeed lead to a higher expected disutility of climate change damages.

However, this comes to mix up the marginal utility of income along a growth pathway under certainty with the marginal utility of a gain/loss in a lottery (the Von Neumann-Morgenstern utility function). Actually, the Stern's assumption of $\eta=1$ is consistent with empirical estimates in growth models (Fellner 1967, Pearce and Ulph 1994) ${ }^{10}$. The confusion comes from the fact that the curvature of the utility function works as a risk-aversion coefficient, giving a higher weight to lower income outcomes: if, one conjectures that there is a fifty-fifty probability that the per capita income will be either 150 or 180 at a given date (compared to 100 , as of today) then the certainty equivalent of this conjecture is 164.3 (below the 175 average value) assuming a natural logarithm utility function. But this mechanical result from the decreasing marginal utility of income says nothing about what trade-off a society would accept between a risky growth pathway leading to a 180 expected value for income with a high variance and a scenario with a certain 150 income, we will come back to that later ${ }^{11}$.

Actually these disputes tended to argue that Stern was "right", "wrong" or "right for the wrong reasons". But this way of conducting the debate, focussing it on the sole controversy about the PTP gives to the external observer two rather questionable expectations: the first is that it is possible to select somewhat arbitrarily two out of the four canonical parameters of the Ramsey equation ( $\rho$ and $\eta$ ), the second that the uncertainty about the values of these parameters will be reduced to such a level that they will support a reliable CBA on a century time horizon. Beyond, the major drawback of overly focusing on the terms of discounting is perhaps to pass implicitly the message that, for economists, there is no case for climate action unless a low consumption discount rate is selected.

The easiest way of understanding why this message is misleading, even in a pure economic perspective, is to observe that the Ramsey formula derives from a growth model with a single composite good. This oversimplification was legitimate to study the patterns of capital accumulation. As emphasized by Heal (2005), it becomes paradoxical to keep on referring to such a model when examining trade-offs between the environment and consumption without incorporating the environment as an argument of the utility function. This leads to neglect: a) how the willingness to pay for environmental amenities may increase as future generations become richer and as these amenities may deteriorate under the threats of climate change; b) the utility losses of our descendants for not

$10 \quad$ Note that Hope (2008) showed that this revision of the value of $\eta$ does not change drastically the results because the effect of the discount rate outweighs the uncertainty effect in the PAGE model.

11 A well-accepted framework allowing to disentangle those two dimensions is still lacking. An attempt is made in Lecocq and Hourcade (2003) in a two period model. The same type of confusion is made when $\eta$ is interpreted as a measure of aversion to interpersonal inequality. 
using areas which would have become uninhabitable (foregone option value), c) the preference for not departing too much from familiar climates which one is more or less adapted to ${ }^{12}$, including the option values of various environmental assets and the ethical reluctance to launch experiments with our only planet Earth which may look like a Faustian bargain.

At the same aggregate level of analysis of the interplays between preferences and technology and within the same vision of a balanced growth pathway, using a $U(C, E)$ utility function makes clearer that the trade-off between current and future consumption changes over time and is not driven solely by the PTP coefficient. It also depends on the decreasing marginal utility of consumption, which makes the environment become a superior good beyond a certain income level (Guesnerie, 2004). The present value of long-term damages then results from two antagonistic forces, the deflating effect of the PTP and the inflating effect of the increasing marginal utility of the environmental good preservation relative to consumption. A similar insight has been given by Sterner and Persson (2007) who report that future scarcities that will be induced by the changing composition of the economy and climate change should lead to rising relative prices for certain goods and services, raising the estimated damage of climate change and counteracting the effect of discounting. They show that taking relative prices into account can have as large an effect on economically warranted abatement levels as can a low discount rate, an intuition already explored by Tol (1994).

To sum up, in a model incorporating a more complete description of preferences, the justification of climate action is less totally dependent upon the pure preference for the present.

\section{2. 'One shot' or sequential decision? The role of the value of information and of the shape of the damage curve}

A second set of reasons for not overshadowing the assessment of climate policies by an extreme focus on the discount rate relates to the way uncertainty is dealt with and more precisely to the decisionmaking framework adopted in the context of an 'ocean of uncertainty'.

Each of the thousand scenarios of the Stern's Monte-Carlo analysis results from a 'one shot' decision as if a climate policy had to be designed today for the entire century. The Weitzman's response to Stern (Waitzman, 2007b) fits in this 'one shot' framework and finds a justification for action in the "thickness" of the tail of the probability distribution of catastrophes. This is an interesting case of the infinite variance syndrome (Mandelbrot 1971, 1973) whereby a combination of uncertain parameters with finite variance may lead mathematically to an outcome of infinite variance, in this case the amount of present consumption the agent would be willing to give up in the present period to obtain one extra sure unit of consumption in the future period.

As underlined by Mandelbrot, this mathematical construct does not imply the existence of an infinite loss in the real world. It is rather a syndrome which signals the limits of the stochastic calculus and the necessity to resort to judgments about safety thresholds to be respected to avoid uncontrollable outcomes (this is of common practice in civil engineering). But Weitzman's interpretation differs and comes to say that, in the presence of a significant PTP and in the absence of environment in the utility function, the justification for action lies in demonstrating that climate change may lead to an infinite

\footnotetext{
${ }^{12}$ An attempt in this direction can be found in Ambrosi et al. (2003) who include the magnitude of climate change in the utility function to translate a willingness to pay for not interfering with the climate system.
} 
pricing for future costs and benefits. But such a demonstration may not make consensus in due time and is greatly dependent upon assumptions about the adaptive capacity of societies (see section 3 below). We know, since the Trojan War that Cassandra is not always convincing and the question is thus, whether, or not, the consideration of a possible a catastrophe is a prerequisite for acting.

Clearly not if one retains the framework proposed by the $2^{\text {nd }}$ and $3^{\text {rd }}$ IPCC reports. This framework states that given uncertainty about both damages and mitigation costs, the issue cannot be to find an optimal pathway over the century in a once for all decision. It consists in a sequential decisionmaking approach defining a short-term response pathway that preserves the possibility of mid-course corrections in function of new information (e.g. switching towards tighter concentration targets in case of bad news about climate risks): "The choice of abatement paths involves balancing the economic risks of rapid abatement now (that premature capital stock retirement will later be proved unnecessary) against the corresponding risk of delay (that more rapid reduction will then be required, necessitating premature retirement of future capital stock). » (IPCC 1996).

In such a framing the value of information (i.e. the value of preserving flexibility) proves to be at least as crucial as the discount rate or the value of the environment relative to that of the composite good. This point, highlighted by Manne and Richels in Buying Greenhouse Insurance (1992) ${ }^{13}$ was exemplified in a debate in Nature between Wigley, Richels and Edmonds (1996) on one side, Ha Duong, Grubb and Hourcade (1997) on the other. The latter showed that considering $550 \mathrm{ppm}$ as the expected value across a range of $450 \mathrm{ppm}, 550 \mathrm{ppm}$ and $650 \mathrm{ppm}$ stabilisation target options, rather than as a deterministic target, makes a significant difference for the short term optimal pathway because of the cost of accelerated action if $450 \mathrm{ppm}$ proves to be the desirable target. In this analysis the discount rate matter but it does so in conjunction with a) the inertia of the technical system which acts as a cost multiplier, should mitigation efforts accelerate between $t-1$ and $t$, b) the date of arrival of information (the more belated this information is expected to be, the more aggressive short term action has to be) and c) the subjective probability attached to each target.

Intuitively, unless the environment is included in the utility function, one can expect that what is true in a stochastic cost-effectiveness analysis (where concentration or temperature ceilings are used as a proxy of damages) may not hold in a stochastic cost-benefit framework. A ceiling indeed, which acts as a surrogate of the benefits of action is not impacted by discounting, whereas discounting changes the monetary values of avoided damages. Actually literature (Fisher et al., 2007, pp 234-236) suggests that this intuition is confirmed only under specific assumptions about the shape of the damage curve (Ambrosi et al., 2003).

With quadratic or hockey-stick functions indeed large damages occur far in the future and, unless they tend to infinity, do not justify early action for any significant long run social discount rate (say higher than $2 \%$ ). Conversely, if the damage curve presents thresholds, these discount rates are compatible with significant short-term action even without assuming large catastrophes. The main reason is that high values of climate sensitivity bring forward the time to reach these thresholds (see Fig. 1 and Fig. 2) which in turn increases the present value of damages. Given the delay of maturation of infrastructure programs on the mitigation side, this can suffice in concluding to the necessity of an early action to change their carbon content.

\footnotetext{
${ }^{13}$ This insurance metaphor is in part misleading because in this case there is no insurance company you can contract with to be covered in case of adverse hazard.
} 


\section{Profile and magnitude of damages: questions of transitory disequilibrium and expectations}

The question thus becomes this of the origins of such thresholds in the deployment of damages. At this stage, the main source of misunderstanding between economists and many other scientists, which pervades in the WGII of the Ipcc report, is that non-linearities in the response of ecosystems (lato sensu i.e. including human-made urban ecosystems) to climate change are obviously critical but are not per se a social cost. Damages are negligible indeed if societies on which impacts befall are totally flexible and can adapt quickly. This flexibility depends on the inertia of pre-existing capital stocks but also on the institutional capacity of societies (including their anticipation skills).

If the economy is on a stable and high growth development pathway and can easily catch up in case of environmental shock after having adapted its infrastructures, then climate change will matter only facing with extreme assumptions (all the more so as we assume rational expectations and fully operational insurance markets). Instead, if the impacted society is fragile, with myopic behavioural routines, and if technical and social inertia prevent an easy return to the equilibrium growth pathway, a cost amplifying effect may create an important wedge between a direct impact and its ultimate consequences on welfare (Hallegatte et al. 2007b).

Assuming economies will adapt easily to climate change comes to neglect (i) uncertainty in regional climate predictions is one order of magnitude larger than in global predictions, (ii) the masking effect of climate variability may lead to detect too late or to misinterpret climate signals (iii) the capitalintensive nature and the inertia of adaptation measures (e.g. dams or building norms) entail risks of sunk costs of mal-adaptation due to wrong expectations regarding the rate and direction of climate change and/or to institutional failures and technical barriers to adaptation (Hallegatte et al. 2007a).

In sum, methodologies assuming perfect foresight and optimal long run responses de facto assess the cost of a "changed climate" and fail to capture the transition costs of adapting to a changing climate and its trial and error process. These costs may be exacerbated under volatile climate signals such as demonstrated by Kelly et al (2005) for the Midwest agriculture. Actually, be it in the field of environment (Tol et al 1998, Schneider 2000) or in the field of energy (Hasset 1993) there are many examples of which the rational expectation with Bayesian learning hypothesis is not an acceptable caricature of reality. Again, removing this hypothesis makes the choice of the discount rate less critical for the valuation of damages..

The ultimate methodological question emerging from this diagnosis relates to the very nature of the 'growth engine' underpinning the use of the Ramsey equation. This growth engine, the same as the Solow growth model, is very helpful to describe equilibrium growth pathways but not situations in which a deviation from this equilibrium cannot be easily (Solow, 1987). This is a matter of capturing transitional disequilibria and not solely of describing 'after adaptation' new equilibria (Hallegate et al, 2007b). But this possibility of uneven growth pathways forces in turn to revisit the preference structure used to assess the welfare implications of environmental shocks. A regular increase in income from 100 to 150 in the course of 25 years does not have the same welfare implications as an erratic income pathway growing from 100 to 130, then regressing to 125 before a recovery up to 160 and a final regression to 150. Each significant economic slow down carries indeed social tensions: a monthly $€ 3,000$ is an achievement for someone earning €2,000 and a frustrating regression by 
someone previously earning $€ 3,500$. The difficulty is to adequately account for downward revisions of growth in aggregate measures of welfare variations: a back of the envelope calculation of the cost (assuming a calculus conducted in 1871) of the First World War for France gives $-0.3 \%$ of discounted GDP over one century! Shall we conclude that this bloody war was such a small cost for France (Jaeger et al, 2008)? In the same way, the total GDP losses of the Marmara earthquake is 2\% only after several years of recovery (see World Bank, 1999). Does this mean that the welfare losses were almost zero? Despite advances carried over with the use of recursive utility function (Ha-Duong et al, 2004), progress remains to be made to capture social preferences for a steady and smooth growth pathway ${ }^{14}$.

\section{Individual weighting and intragenerational equity: benevolence or intérêts bien compris?}

Another, less frequent, criticism to the Stern Review is addressed to its use of unitary weighting in aggregating individual welfare variations into the social welfare function. The issue is obvious: since most of the climate change impacts fall on the developing world, this weighting results in a higher value of aggregate damages than under the conventional practice of using Negishi coefficients which weight individuals in proportion of their income and gives a lesser value to the damages incurred by poorer populations.

The ethical justification of the unitary weighting is not as obvious as it seems at first glance. Indeed, given the assumption of decreasing marginal individual utility of income, the benevolent planner in charge of maximizing a social welfare function with such a weighting will charge all the burden of climate policies to richer individuals as long as the levels of income are not equated. Beyond its lack of political realism, this solution can be rejected on normative grounds. Even though there is legitimate question about the actual distribution of income, there is no specific argument to correct it at the occasion of climate policies ${ }^{15}$.

Actually, a unitary weighting of individuals is a problematical response to the ethical difficulties raised by the use of Negishi weights to impose a no-redistribution constraint to the benevolent planner. This difficulty can be in part mitigated by a realistic description of damage propagation across regions and by a discussion of the attitude of countries vis-à-vis climate impacts falling beyond their boarders (Lecocq and Hourcade, 2004). Many examples given in the Stern Review suggest that severe damages on one region may propagate to neighbouring regions, for instance through an intensification of international migration flows. Richer countries should thus consider not only impacts befalling within their own borders but also the ultimate consequences, including security issues, of damages befalling on poorer countries. Logically, this part of the total damages propagating to the richer countries should be accounted with their Negishi weights. This comes to upgrade the value of climate change impacts falling on the poorer without being exposed to the criticisms of using unrealistic egalitarian ethical judgments and of "imposing value judgments to the rest of the world".

This implies a form of universal solidarity ethic which may result from a benevolent or altruistic attitude of rich countries or, more cynically, from a due accounting of their intérêts bien compris.

\footnotetext{
${ }^{14}$ One attempt in this direction was proposed by Chichilnysky et al. (1995)

${ }^{15}$ This is why the Second Assessment Report of the IPCC (Stiglitz et al., 1995, spm) cautiously stands on the statement that "for the purposes of the analysis, it is possible to separate efficiency from equity."
} 


\section{Conclusion: intertwined challenges for IA modelling and economic theory}

The above analysis suggests that criticisms to the Stern review that focus on the choice of a very low pure time preference, of a unitary value for the curvature of the utility function and of a unitary weighting of individuals are both relevant and misplaced. They are relevant because they emphasize the disputable character of these parametric choices; they are partly misplaced because they do not use the Stern review, a risky venture within the limits of the economists' toolbox, as an intellectual challenge to detect the methodological advances needed to address the deficiencies of this toolbox and its use in integrated assessment exercises, some of these advances being also worth considering in any alternative approach to integrated assessment.

These can be first expressed in the language of the Arrow-Debreu axiomatic: the pure time preference is one price (the exchange rate between any asset at $t+1$ and the same asset at $t$ ) amongst others at any point in time: the value of environmental amenities relative to consumption and the value of information which itself depends on a broad set of parameters and beliefs about the magnitude and pace of deployment of damages, about inertia which governs how abatement costs at a time $t$ depend on previous abatement efforts (Gerlagh et al., 2003) and about the pace of resolution of uncertainty. We thus need a new generation of IAMs capable of a rigorous accounting of this full set of prices and a richer description of preferences, including the preference for 'smooth' growth pathways.

But the discussion cannot go very far though without growth models that do not take the stability of growth pathways for granted. The crux of the matter, indeed, is to capture transitory disequilibria, in particular provoked by decisions under imperfect expectations that entail large technico-economic inertia and potential lock-ins. Accounting for transient disequilibria and sub-optimalities in both baselines and policy scenarios may lead, on top of upgrading the monetary estimates of damages, to better reflect the potential development dividend of mitigation policies yielded by reducing some of the disequilibria prevailing in the no-policy scenario (for example upgrading the resilience to oil shocks, see Shukla et al, 2001).

Beyond, the question remains of how to deal with potentially large but weak probability hazards that may result in thick tails of the probability distribution of damages. Actually, interpreting the infinite variance syndrome as reflecting the limitations of the Bayesian approach may facilitate the dialogue between integrated assessment approaches that rely on the conventional cost-benefit framework and those who prefer inverse modelling (Tóth 2003). In this dialogue, and even though there has been so far no significant attempt to use imprecise probability approaches in this field, these could be explored further to produce methods (of expert fusions for example), that do not rule out a priori an event being assigned almost zero probability in the prior distribution (Ha Duong, 2005).

These advances will not change the crude fact that there is no hope to reach a consensus in due time (over the next two decades) on the raw material of any integrated further integrated assessment, i.e. ethical parameters, growth regimes, magnitude of climate change impacts, adaptive capacities of societies. Since a consensus for an adequate action has to be reached despite such divergences, these advances are urgent, either within the conventional economic toolbox or within alternative approaches, to detect better the mechanisms at play in the formation of climate change damages and disentangle what controversy really matter and which does not.. This is a precondition for integrated assessment 
models be of use to clarify what compromise should be made among controversial worldviews and opposite interests about the desirable course of action in the following two decades, prior to the extinction of the ocean of uncertainty that surrounds climate change.

\section{REFERENCES}

- Ambrosi, Ph., J.C. Hourcade, S. Hallegatte, F. Lecocq, P. Dumas, and M. Ha Duong. (2003). "Optimal control models and elicitation of attitudes towards climate damages." Environmental Modeling and Assessment, 8:3, pp. 133-47.

- Arrow, K., 1996 in: Climate Change 1995 - Economic and Social Dimensions of Climate Change, James P. Bruce and Hoesung Lee and Erik F. Haites editors, Cambridge University Press.

- Chichilnisky, G., Heal G., Beltratti A. (1995), 'The Green Golden Rule', Economics Letters, 49: 175-179.

- Dasgupta, P.. 2006. Comments on the Stern Review’s Economics of Climate Change. Available at www.econ.cam.ac.uk/faculty/dasgupta/STERN.pdf

- Dasgupta, P., K.-G. Maler and S. Barrett (1999). Intergenerational Equity, Social Discount Rates, and Global Warming. in P.R. Portney and J.P. Weyant, eds., Discounting and Intergenerational Equity (Washington DC: Resources for the Future).

- Fellner W. (1967). Operational utility; the theoretical background and measurement, in Fellner W. (ed.) Ten Economic Studies in the Tradition of Irving Fisher New York: John Wiley.

- Fisher, B.S., N. Nakicenovic, K. Alfsen, J. Corfee Morlot, F. de la Chesnaye, J.-Ch. Hourcade, K. Jiang, M. Kainuma, E. La Rovere, A. Matysek, A. Rana, K. Riahi, R. Richels, S. Rose, D. van Vuuren, R. Warren, 2007: Issues related to mitigation in the long term context, In Climate Change 2007: Mitigation. Contribution of Working Group III to the Fourth Assessment Report of the Inter-governmental Panel on Climate Change [B. Metz, O.R. Davidson, P.R. Bosch, R. Dave, L.A. Meyer (eds)], Cambridge University Press, Cambridge.

- Gerlagh, R., and B. van der Zwaan, (2003) Gross world product and consumption in a global warming model with endogenous technological change, Resource and Energy Economics, 25: $35-57$.

- Gollier, C., 2006. "Climate Change And Insurance: An Evaluation Of The Stern Report On The Economics Of Climate Change.” Barbon Institute: December.

- Guesnerie, R. 2004. Calcul économique et développement durable, La Revue Economique

- Ha-Duong M, Grubb M., Hourcade JC. (1997) Influence of socioeconomic inertia and uncertainty on optimal CO2-emission abatement, Nature, 390:270-274.

- Ha-Duong M, Treich, N. (2004) Risk aversion, intergenerational equity and climate change, Environmental and Resource Economics, 28(2):195-207. 
- Ha-Duong M., Modèles de précaution en économie: introduction aux probabilités imprécises. Mémoire d'habilitation à diriger les recherches, Université de Paris I, Décembre 72005.

- Hallegatte, S., Hourcade, J.-C., and Ambrosi P., 2007a, Using climate analogues for assessing climate change economic impacts in urban areas, Climatic Change, 82(1-2), pp. 47-60.

- Hallegatte, S., Hourcade, J.-C., and Dumas P., 2007b, Why economic dynamics matter in assessing climate change damages: illustration on extreme events, Ecological Economics, 62, pp. 330-340.

- Hahn H. Frank 1990 Solowian Growth Models in Growth/Productivity/Unemployment, Essays to Celebrate Bob Solow's Birthday, P. Diamond (Ed), The MIT press

- Hassett, Kevin A. and Metcalf, Gilbert E., 1993. "Energy conservation investment: Do consumers discount the future correctly?," Energy Policy, vol. 21(6), pages 710-716, June.

- Heal Geoffrey 2005, Intertemporal welfare economics and the environment, in Handbook of Environmental Economics, Volume 3, K.-G. Maler and J.R. Vincent (Eds), Elsevier.

- Hope, C. (2008) Discount rates, equity weights and the social cost of carbon, Energy Economics, 2008, vol. 30, issue 3, pages 1011-1019.

- IPCC (1996) Climate Change 1995: Economic and Social Dimensions of Climate Change, Contribution of Working Group III to the Second Assessment of the Intergovernmental Panel on Climate Change, Summary for Policymakers. Cambridge University Press, UK, J.P. Bruce, H. Lee, E.F. Haites (Eds).

- Jaeger, C. , Schellnhuber, H.J. and Brovkin, V (2008) Stern's Review and Adam's fallacy. Climatic Change 89(3/4) pp 207-218.

- Kelly, David L., Kolstad, Charles D., Mitchell, Glenn T., 2005, Adjustment costs from environmental change. Journal of Environmental Economics and Management 50, 468-495.

- Lecocq F, Hourcade J.C. 2004, Le taux d'actualisation contre le principe de précaution ? Leçons à partir du cas des politiques climatiques, L’Actualité économique Volume 80, nº 1.

- Lecocq F, Hourcade J.C. 2003, Equitable Provision of Long-Term Public Goods: The Role of Negotiation Mandates, World Bank Research Working Paper.

- Mandelbrot B. 1971, When Can Price be Arbitraged Efficiently? A limit to the Validity of the Random Walk in Martingale Models, Review of Economics and Statistics, LIII pp 225 - 236

- Mandelbrot B. 1973, Le Syndrome de la variance infinie, Conférence au Collège de France, 15 janvier 1973 pp 321-348

- Manne, A.S. et R. Richels (1992). Buying Greenhouse Insurance: The Economic Cost of CO2 Emissions limits, MIT Press, Cambridge (MA).

- Mendelsohn, R. O. 2006. A critique of the Stern Report. Regulation Winter: 42-46.

- Mendelsohn, R., Morrison, W., Schlesinger, M., and N. Andronova, 2000, Country-specific market impacts of climate change, Climatic Change, 45, 553-569. 
- Newell, R.G. and A.W. Pizer. 2001. Discounting the benefits of climate change mitigation, 37 p, Pew Center on Global Climate Change, Washington DC.

- Nordhaus, W. D. 2006. A review of the Stern Review on the economics of global warming. Available at http://nordhaus.econ.yale.edu/stern_050307.pdf

- Pearce, David W. and David Ulph (1994), 'A social discount rate for the United Kingdom', Mimeo No. 95-01, Centre for Social and Economic Research on the Global Environment, University College London and University of East Anglia, UK.

- Petschel-Held, G., H.-J. Schellnhuber, T. Bruckner, F.L. Toth et K. Hasselmann (1999). The Tolerable Windows Approach: theoretical and methodological foundations, Climatic Change, 41 (3/4), 303-331.

- Schneider, Stephen H., William E. Easterling, Linda O. Mearns (2000), Adaptation: Sensitivity to Natural Variability, Agent Assumptions and Dynamic Climate Changes, Climatic Change Vol. 45, 203-221

- Solow M.R. (1987), Prize lecture, Growth Theory and After, The Sveriges Risksbank Prize in Economic Sciences in Memory of Alfred Nobel 1987.

- Shukla P.R., Venkata Ramana P., Chandra Shekhar Sinha, (2001) Renewable energy technologies and climate change policies in India, International Journal of Global Energy Issues (IJGEI), Vol. 15, No. $1 / 2$.

- Stern, N., 2006. The Economics of Climate Change. The Stern Review. Cambridge University Press.

- Stern Review team (2007), Value judgements, welfare weights and discounting: issues and evidence. http://www.hm-treasury.gov.uk/media/D/B/stern yaleb091107.pdf

- Sterner, T, and Persson, U. M., 2007, An Even Sterner Review: Introducing Relative Prices into the Discounting Debate, RFF DP 07-37.

- Stiglitz J.E., Arrow K.J., Cline W.R., Goran-Maler K., Munasinghe M., Squiteri R., (1995) The Social Costs of Climate Change : IPCC Working Group III Report, Chapter 4: Intertemporal equity, discounting, and economic efficiency, pp 125-141.

- Stoleru L., L’équilibre et la croissance économique; Dunod Paris 1968.

- Tol, R. S. J., and Yohe. G. W., 2006. A review of the Stern Review. World Economics 7 (4): 233-250.

- Tol, R.S.J., Fankhauser S., and Joel B. Smith (1998) The scope for adaptation to climate change: what can we learn from the impact literature? Global Environmental Change, 8 (2), 109-123;

- Tol, R.S.J., 2002b, New estimates of the damage costs of climate change, Part II: Dynamic estimates, Environmental and Resource Economics, 21 (2), 135-160.

- Tol, R.S.J., 1994, The damage costs of climate change: a note on tangibles and intangibles, applied to DICE, Energy Policy, 22 (5), 436-438. 
- Toth, F.L. (ed.), 2003: Integrated Assessment of Climate Protection Strategies. Climatic Change, Special Issue, 56(1-2).

- Weitzman, M., 1998, Why the Far-Distant Future Should be Discounted at its Lowest Possible Rate, Journal of Environmental Economics and Management, 36(3).

- Weitzman, M., 2007a, The Stern Review of the Economics of Climate Change, Book report commissioned by JEL.

- Weitzman, M., 2007b, The Role of Uncertainty in the Economics of Catastrophic Climate Change, AEI-Brookings Joint Center Working Paper No. 07-11.

- Wigley, T.M.L., Richels, R. and Edmonds, J.A., (1996): Economic and environmental choices in the stabilization of atmospheric CO2 concentrations. Nature 379, 240-243.

- World Bank, 1999, Turkey: Marmara Earthquake Assessment. World Bank Working Paper. 
Global mean temperature rise wrt 1990 (A1m)

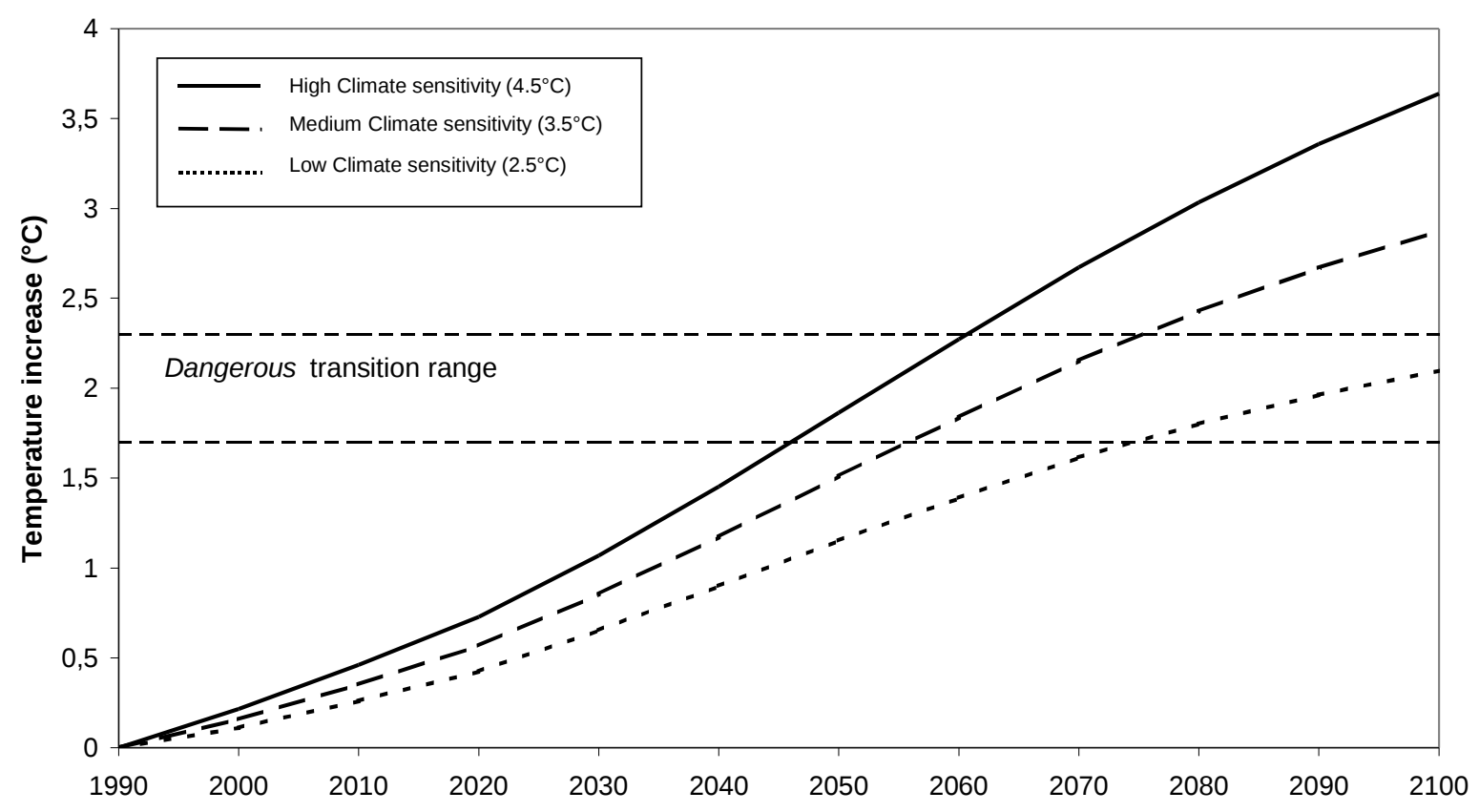

Time of occurrence of abrupt shifts in climate change damages

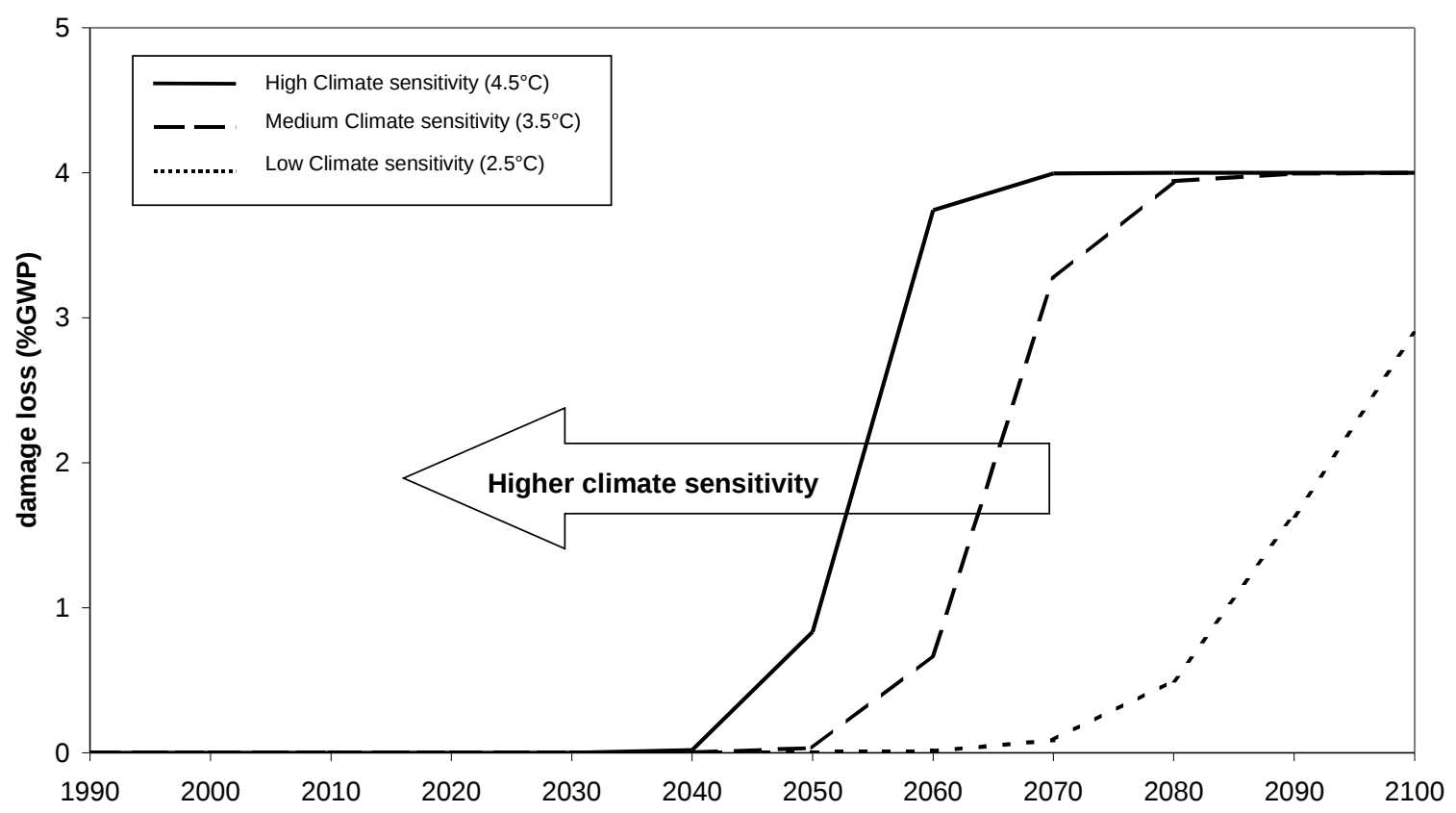

